\title{
The Patterns Use and Attitudes toward Unconventional Medicine among Saudi Young Adults: Cross Sectional Study
}

\author{
Mohammed S. S. Al-Dhubaibi MD ${ }^{1}$, Mahfoudh A.M. Abdulghani PhD ${ }^{2}$, Ghada F. Mohammed \\ $\mathrm{MD}^{3}$, Mahmoud Abdullah Al-Areefi $\mathrm{PhD}^{4}$ \\ ${ }^{I}$ Department of Dermatology College of Medicine, Qassim University, Saudi Arabia \\ 2Department of Pharmacology \& Toxicology, Unaizah College of Pharmacy (UCP), Qassim University, Saudi \\ Arabia \\ ${ }^{3}$ Department of Dermatology and Venereology Faculty of Medicine, Suez Canal University, Ismailia, Egypt \\ ${ }^{4}$ Department of Health Information Management \& Technology, Faculty of Public Health \& Health Informatics, \\ Umm Al Qura University, Makkah, Saudi Arabia
}

*Corresponding Author: Ghada F. Mohammed MD, Department of Dermatology and Venereology, Faculty of Medicine, Suez Canal University, Ismailia, Egypt,Email: Dr_Ghada77@ hotmail.com

\begin{abstract}
Unconventional medicines (UM) are widely used in the Qassim Province. This study to investigate patterns of use and attitudes toward unconventional medicine among young adult enrolled at school of medicine in Qassim University.
\end{abstract}

Methods: A descriptive cross-sectional survey was conducted using adopted questionnaire on a sample of 313 young adults enrolling at the college of medicine.

Result: The response rate was $55.9 \%$. Using of UM was mentioned by $69.1 \%$ of respondents. The most of the respondents $72.4 \%$ indicated that reasons of use UM was treating illness. The most common UM were thought to be holly Quran \& pray, herbal medicine and honey by most of respondents $76.3 \%, 70.3 \%$ and $65.3 \%$ respectively, followed by sports therapy $44.9 \%$, oil therapy $23.7 \%$, nutrition medicine $24.6 \%$, fasting therapy $13.6 \%$, traditional medicine $13.6 \%$, Quipping $7.6 \%$, aromatherapy $6.8 \%$, apiotherapy $4.2 \%$ and Yoga therapy $5.1 \%$. The most common reasons preference of natural substance for treatment were $47 \%$, success of UT $42 \%$ and long waiting for an appointment with specialist or consultant.

Conclusions: Many people consider using different modalities of UM for treatment of illness and wellbeing. Providers caring for young adults should discuss UM with patients, particularly those recognized as likely use UM.

Keywords: Unconventional Therapy, Unconventional Medicine, Questionnaires

\section{INTRODUCTION}

Therapies or examinations which has no scientific basis and demonstrates no effective or diagnostic reliability is referred to unconventional medicine (UM) ${ }^{[1]}$. Various terms are used interchangeably with UM, although different things may be meant UM; include alternative medicine, complementary medicine, holistic medicine, integrative medicine, and naturopathy. UM can be considered as a group of varied medical and health care systems, practices, and products that are not generally considered part of conventional medicine ${ }^{[2]}$. The conventional medicine or allopathy is scientific medicine.
UM comprises many treatment modalities, including acupuncture, aromatherapy, homeotherapy, chiropractic, dietetics, herbalism, megavitamins, yoga, and spiritual healing.

Unconventional therapies are more widespread than ever before ${ }^{[3]}$. Illness is one of the common reasons to use UM. The most common illnesses include cancer, arthritis, chronic back pain, acquired immunodeficiency syndrome, and gastrointestinal problems ${ }^{[1]}$. In Kingdom of Saudi Arabia (KSA), cancer, skin, asthma disease, depression, neurological disorders and chronic pain are common of diseases lead to increase in UM use ${ }^{[4,5,6,7,8]}$. The use of UM in health care is rapidly growing ${ }^{[2]}$. Previous study 
in KSA showed that $42 \%$ of population used UM for their child's condition ${ }^{[6]}$. A recent study in KAS that investigates UM use among the military and their families of Saudi reported that $46 \%$ used UM ${ }^{[5]}$. A recent study that investigates UM use among the neurology patients at King Saud University Ambulatory Clinic reported $67 \%$ used UM ${ }^{[7]}$. Another study in KAS that investigates UM use among the patients attending health clinic centers reported that $36.9 \%$ used $\mathrm{UM}^{[9]}$. The most commonly used UM practices were Cupping (hojamah), herbs, cauterization, honey, and the reciting of the Holy Quran, religious and spiritual healing $[5,6,7]$.

However many studies were reported on population used UM in KSA, but for Saudi young adult was not found up to knowledge of the authors. Since the Saudi young adults represent a proximally $50 \%$ in Qassim Provenance as well as other region in KSA ${ }^{[10]}$. So this study can be serve as a pilot study to make attention of Saudi medical providers on the needs to introduce UM into the health care system. This study to investigate patterns of use and attitudes toward unconventional medicine among young adult enrolled at school of medicine in Qassim University

\section{MATERIAL AND METHODS}

The study population consisted of first year medical college, Qassim university who, at the time of the study (2015-2016). After giving written informed consent, participants completed a self-administered questionnaire. The study population group was selected due to lack of knowledge of medical prescriptions, and lack of knowledge of varieties of drug therapy. The questionnaire was designed to be completed in five to ten minutes.

The three-page instrument consisted of sixteen questions with a check-box format. The questionnaire has been divided in to three parts. Part A: information about the student which include age, gender, marital status and health status. Part B: information about unconventional therapies and providers that the students used. Part C: information about beliefs towards (unconventional therapies) use ${ }^{[11]}$.

\section{Data Analysis}

Responses to each survey item on the UM questionnaire were graphed and the frequencies were examined. Following descriptive analysis, the data were examined for internal consistency by exploring item-total correlations. Frequencies were used to describe respondent background characteristics.

\section{Results}

Of the total 313 questionnaires distributed to all medical students at Qassim University present during the study period, i.e. 1 June 2012-31 July 2012, 175medical students were returned giving a response rate of $55.91 \%$. The majority of the respondents were male $(\mathrm{n}=100,57.1 \%)$. Aged between 15 to 20 years $(n=135,77.1 \%)$ and between 21 to 25 years $(n=40,22.9 \%)$. Among the respondents, $100(57.1 \%)$ were males and 75 $(42.9 \%)$ were females.

In Table 1: $69.1 \%$ of respondents mention that use unconventional therapy in their life. The respondents indicate that $73.6 \%$ of the unconventional therapy practitioners who visited by respondents do not holding certificate or license and only $5.8 \%$ only holding certificate or license. The most of the respondents indicate that reasons of use unconventional medicine was treating illness $72.4 \%, 38.8 \%$ of respondents for promoting and the other $25.9 \%$ indicate for preventing illness. The most of respondents $93.1 \%$ shown that get their information about UM from family members and/or friend. Some respondents get their UM information from internet $24.1 \%$, advertising $8.6 \%$ and $9.5 \%$ from book. The most common reasons preference of natural substance for treatment $47 \%$, success of UT $42 \%$ and long waiting for an appointment with specialist or consultant. The most common UM were preferred by respondents included holly Quran/Roqua/ pray76.3\%, herbal medicine $70.3 \%$ and honey $65.3 \%$, followed by sports therapy $44.9 \%$, oil therapy $34.7 \%$, nutrition medicine $24.6 \%$, massage therapy $23.7 \%$ fasting therapy $13.6 \%$, traditional medicine $13.6 \%$, Quipping 7.6\%, aromatherapy $6.8 \%$, apiotherapy $4.2 \%$ and Yoga therapy $5.1 \%$ (Table 2). 
The Patterns Use and Attitudes toward Unconventional Medicine among Saudi Young Adults: Cross Sectional Study

Table1. Questions on UM and responses.

\begin{tabular}{|c|c|c|c|c|}
\hline & Questions & Responses & $\mathrm{N}$ & $\%$ \\
\hline \multirow[t]{3}{*}{ (6) } & \multirow{3}{*}{$\begin{array}{c}\text { Did you ever use } \\
\text { unconventional } \\
\text { therapy in your life? }\end{array}$} & yes & 121 & 69.1 \\
\hline & & no & 54 & 30.9 \\
\hline & & Total & 175 & 100.0 \\
\hline & \multirow{5}{*}{$\begin{array}{l}\text { Is a person holding a } \\
\text { certificate or license }\end{array}$} & Yes & 7 & 5.8 \\
\hline & & No & 89 & 73.6 \\
\hline & & I don't Know & 20 & 16.5 \\
\hline & & Total & 116 & 95.9 \\
\hline & & Missing system & 5 & 4.1 \\
\hline & \multirow{4}{*}{$\begin{array}{c}\text { Source of } \\
\text { information for use } \\
\text { UM }\end{array}$} & Book & 11 & 9.5 \\
\hline & & Advertising & 10 & 8.6 \\
\hline & & Internet & 28 & 24.1 \\
\hline & & $\begin{array}{c}\text { Family } \\
\text { member/friends }\end{array}$ & 108 & 93.1 \\
\hline & \multirow[t]{4}{*}{ Reasons for use UM } & $\begin{array}{c}\text { Preventing } \\
\text { illness }\end{array}$ & 30 & 25.9 \\
\hline & & Treating illness & 84 & 72.4 \\
\hline & & $\begin{array}{c}\text { Promoting } \\
\text { health }\end{array}$ & 45 & 38.8 \\
\hline & & Other & 2 & 1.7 \\
\hline
\end{tabular}

Table2. Types of unconventional medicine used by young adults.

\begin{tabular}{|c|c|c|c|}
\hline & Type of UM & $\mathrm{N}$ & $\%$ \\
\hline 1 & Quran, Roqua, Salah & 90 & 76.3 \\
\hline 2 & Herbal medicine & 83 & 70.3 \\
\hline 3 & Honey & 77 & 65.3 \\
\hline 4 & Sports therapy & 53 & 44.9 \\
\hline 5 & Oil therapy & 41 & 34.7 \\
\hline 6 & Nutrition medicine & 29 & 24.6 \\
\hline 7 & Massage Therapy & 28 & 23.7 \\
\hline 8 & Fasting therapy & 16 & 13.6 \\
\hline 9 & Traditional medicine & 16 & 13.6 \\
\hline 10 & Cupping & 9 & 7.6 \\
\hline 11 & Aromatherapy & 8 & 6.8 \\
\hline 12 & Yoga therapy & 6 & 5.1 \\
\hline 13 & Apiotherapy & 5 & 4.2 \\
\hline 14 & Cauterization & 5 & 4.2 \\
\hline 15 & $\begin{array}{c}\text { Alternative medicinal } \\
\text { urine \& milk therapy }\end{array}$ & 4 & 3.4 \\
\hline 16 & Osteopathy & 3 & 2.5 \\
\hline 17 & Reflexology & 2 & 1.7 \\
\hline 18 & Magnet therapy & 2 & 1.7 \\
\hline 19 & Acupuncture & 1 & 0.8 \\
\hline 20 & Electromengenatic & 1 & 0.8 \\
\hline 21 & Traditional Chinese & 1 & 0.8 \\
\hline 22 & therapy & & 0.8 \\
\hline Resper & 1 & \\
\hline
\end{tabular}

Respondents showed a positive attitudes toward unconventional medicine that $41(23.4 \%)$ agreed and strong agree $8(4.6 \%)$ about unconventional medicine providers give good information on maintaining a healthy lifestyle. The respondents believed 82 (46.8\%), $77(44 \%)$ and 46 (26.3) that there are less side effects when taking natural remedies, unconventional medicine involves natural plant formulas which are more healthy than taking drugs given by the medical doctor and unconventional medicine builds up the body's own defenses and promotes selfhealing. The respondents strongly disagree and disagree 9051.4 that they would be more likely to use unconventional medicine if there were more unconventional medicine clinics. the respondents $55(31.5 \%)$ agree that the more knowledge a young adult has about Unconventional medicine, the more likely he/she is to use it. The most of respondents 143 $(81.7 \%)$ agree that parent(s) and family can influence a young adult's unconventional medicine use by exposing them to it. $93(53.1 \%)$ and 94 (53.7) agree that they are more likely to use unconventional medicine if their friends are using it and if coaches and teachers discuss it with them (Table 3).

Table3. Young adults' attitudes toward unconventional medicine.

\begin{tabular}{|c|c|c|c|c|c|c|}
\hline & & $\begin{array}{c}\text { Strongl } \\
\mathrm{y} \\
\text { disagre } \\
\mathrm{e}\end{array}$ & $\begin{array}{l}\text { Disa } \\
\text { gree }\end{array}$ & $\begin{array}{c}\text { Haven } \\
\text { 't } \\
\text { decide } \\
d\end{array}$ & $\begin{array}{c}\text { Agre } \\
\mathrm{e}\end{array}$ & $\begin{array}{c}\text { Strong } \\
\text { ly } \\
\text { agree }\end{array}$ \\
\hline 1 & $\begin{array}{l}\text { Unconventi } \\
\text { onal } \\
\text { medicine } \\
\text { providers } \\
\text { give good } \\
\text { information } \\
\text { on } \\
\text { maintaining } \\
\text { a healthy } \\
\text { lifestyle }\end{array}$ & $\begin{array}{c}26 \\
(14.9)\end{array}$ & $\begin{array}{c}46 \\
(26.3 \\
)\end{array}$ & $\begin{array}{c}54 \\
(30.9)\end{array}$ & $\begin{array}{c}41 \\
(23 . \\
4)\end{array}$ & $\begin{array}{c}8 \\
(4.6)\end{array}$ \\
\hline 2 & $\begin{array}{l}\text { There are } \\
\text { less side } \\
\text { effects } \\
\text { when taking } \\
\text { natural } \\
\text { remedies }\end{array}$ & $\begin{array}{c}14 \\
(8.0)\end{array}$ & $\begin{array}{c}30 \\
(17.1 \\
)\end{array}$ & $\begin{array}{c}49 \\
(28.0)\end{array}$ & $\begin{array}{c}65 \\
(37 . \\
1)\end{array}$ & $\begin{array}{c}17 \\
(9.7)\end{array}$ \\
\hline 3 & $\begin{array}{l}\text { Unconventi } \\
\text { ona } \\
\text { lmedicine } \\
\text { involves } \\
\text { natural plant } \\
\text { formulas } \\
\text { which are } \\
\text { more } \\
\text { healthy than } \\
\text { taking drugs } \\
\text { given by the } \\
\text { medical } \\
\text { doctor }\end{array}$ & $15(8.6)$ & $\begin{array}{c}23 \\
(13.1 \\
)\end{array}$ & $\begin{array}{c}60 \\
(34.3)\end{array}$ & $\begin{array}{c}65 \\
(37 . \\
1)\end{array}$ & $\begin{array}{c}12 \\
(6.9)\end{array}$ \\
\hline 4 & $\begin{array}{l}\text { Young } \\
\text { adults } \\
\text { would be } \\
\text { more likely } \\
\text { to use }\end{array}$ & $\begin{array}{c}30 \\
(17.1)\end{array}$ & $\begin{array}{c}60 \\
(34.3 \\
)\end{array}$ & $\begin{array}{c}54 \\
(30.9)\end{array}$ & $\begin{array}{c}26 \\
(14 . \\
9)\end{array}$ & $\begin{array}{c}5 \\
(2.9)\end{array}$ \\
\hline
\end{tabular}


herbal medicine and honey therapy. Providers caring for young adults should discuss UM with patients, particularly those recognized as likely use UM. Further studies should investigate UM are taken along with conventional therapies.

\section{LIMITATIONS}

The limitations of our study like survey based study, a convenient sample of respondents from first year college of medicine so the outcome of the study cannot generalized. Some of the participants may have been inaccurate. The outcome of the study was relied on self-reports by young adults and could not independently verify the information that was reported. The data were collected from one province, findings may differ in other geographically groups of young adult.

\section{ACKNOWLEDGMENTS}

The authors would like to thank first year medical students for their participation in the study.

\section{REFERENCES}

[1] Eisenberg DM, Kessler RC, Foster C, Norlock FE, Calkins DR, Delbanco TL. Unconventional medicine in the United States--prevalence, costs, and patterns of use. New England journal of medicine. 1993;328(4):246-52.

[2] Loh KP, Ghorab H, Clarke E, Conroy R, Barlow J. Medical students' knowledge, perceptions, and interest in complementary and alternative medicine. The journal of alternative and complementary medicine. 2013; 19(4):3606.

[3] Ernst E. The usage of complementary therapies by dermatological patients: a systematic review. British Journal of Dermatology. 2000;142(5):857-61.

[4] Al Moamary MS. Unconventional therapy use among asthma patients in a tertiary care center in Riyadh, Saudi Arabia. Annals of thoracic medicine. 2008;3(2):48.

[5] Al-Faris EA. The pattern of alternative medicine use among patients attending health centres in a military community in Riyadh. Journal of Family and Community Medicine. 2000;7(2):17.

[6] Jan MM, Basamh MS, Bahassan OM, JamalAllail AA. The use of complementary and alternative therapies in Western Saudi Arabia. Saudi medical journal. 2009;30(5):682-6.
[7] Mohammad Y, Al-Ahmari A, Al-Dashash F, et al. Pattern of traditional medicine use by adult Saudi patients with neurological disorders. BMC complementary and alternative medicine. 2015;15(1):102-7.

[8] Al Moamary MS. Unconventional therapy use among asthma patients in a tertiary care center in Riyadh, Saudi Arabia. Annals of thoracic medicine. 2008;3(2):48.

[9] Almousa H, Rabie FM, Alsamghan AS, et al. Prevalence, Types and Determinants of Complementary and Alternative Medications among Health Clinic Clients. Journal of Education and Practice. 2015;6(18):51-8.

[10] AlBedah AM, Khalil MK, Elolemy AT, et al. The use of and out-of-pocket spending on complementary and alternative medicine in Qassim province, Saudi Arabia. Annals of Saudi Medicine. 2013;33(3):282.

[11] Patterson C, Arthur H. A complementary alternative medicine questionnaire for young adults. Integrative medicine insights. 2009;4:1.

[12] Cotton S, Luberto CM, Yi MS, Tsevat J. Complementary and alternative medicine behaviors and beliefs in urban adolescents with asthma. Journal of Asthma. 2011;48(5):531-8.

[13] Reznik M, Ozuah PO, Franco K, Cohen R, Motlow F. Use of complementary therapy by adolescents with asthma. Archives of pediatrics \& adolescent medicine. 2002;156(10):1042-4.

[14] Wootton JC. WHO global atlas of traditional, complementary and alternative medicine. Journal of Alternative \& Complementary Medicine. 2006;12(1):93-4.

[15] Awad A, Al-Shaye D. Public awareness, patterns of use and attitudes toward natural health products in Kuwait: a cross-sectional survey. BMC complementary and alternative medicine. 2014;14(1):105.

[16] Barnes PM, Bloom B, Nahin RL. Complementary and alternative medicine use among adults and children: United States, 2007. US Department of Health and Human Services, Centers for Disease Control and Prevention, National Center for Health Statistics Hyattsville, MD, 2008.

[17] Clarke TC, Black LI, Stussman BJ, Barnes PM, Nahin RL. Trends in the use of complementary health approaches among adults: United States, 2002-2012. National health statistics reports. 2011(79): 1 .

[18] Hunt KJ, Coelho HF, Wider B, et al. Complementary and alternative medicine use in England: results from a national survey. International journal of clinical practice. 2010;64(11):1496-502. 
The Patterns Use and Attitudes toward Unconventional Medicine among Saudi Young Adults: Cross Sectional Study

[19] Patterson C, Arthur H, Noesgaard C, et al. Exploring adolescent complementary/ alter znative medicine (CAM) use in Canada. Journal of inter professional care. 2008; 22(1):45-55.
[20] Naja F, Alameddine M, Itani L, Shoaib H, Hariri D, Talhouk S. The use of complementary and alternative medicine among lebanese adults: results from a national survey. Evidence -Based Complementary and Alternative Medicine.2015;2015.

Citation: Mohammed S. S. Al-Dhubaibi MD, Mahfoudh A.M. Abdulghani PhD, Ghada F. Mohammed MD, Mahmoud Abdullah Al-Areefi PhD. The Patterns Use and Attitudes toward Unconventional Medicine among Saudi Young Adults: Cross Sectional Study ARC Journal of Public Health and Community Medicine. 2017; 2(3):7-12. doi:dx.doi.org/10.20431/2456-0596.0203002.

Copyright: (C) 2017 Authors. This is an open-access article distributed under the terms of the Creative Commons Attribution License, which permits unrestricted use, distribution, and reproduction in any medium, provided the original author and source are credited. 